\title{
BMJ Global Health Multisectoral governance for health: challenges in implementing a total ban on chrysotile asbestos in Thailand
}

\author{
Churnrurtai Kanchanachitra, ${ }^{1}$ Viroj Tangcharoensathien, ${ }^{2}$
} Walaiporn Patcharanarumol, ${ }^{2}$ Tipicha Posayanonda ${ }^{3}$

\begin{abstract}
To cite: Kanchanachitra C, Tangcharoensathien V, Patcharanarumol W, et al. Multisectoral governance for health: challenges in implementing a total ban on chrysotile asbestos in Thailand. BMJ Glob Health 2018;3:e000383. doi:10.1136/ bmjgh-2017-000383
\end{abstract}

Handling editor Seye Abimbola

Received 25 April 2017 Revised 5 March 2018 Accepted 11 March 2018

Check for updates

${ }^{1}$ Institute for Population and Social Research, Mahidol University, Salaya, Thailand ${ }^{2}$ Ministry of Public Health, International Health Policy Program, Nonthaburi, Thailand ${ }^{3}$ National Health Commission Office, Nonthaburi, Thailand

Correspondence to Professor Churnrurtai Kanchanachitra; churnrurtai.kan@mahidol.edu

\section{ABSTRACT}

Introduction Interest in multisectoral governance for health has grown in recent years in response to the limitations of government-centric policy formulation and implementation. This study describes multisectoral governance associated with policy formulation and implementation of a total ban on chrysotile asbestos in Thailand.

Methods Qualitative methods were applied, including analysis of related literature and media, and in-depth interviews with key informants. Consent was obtained for interview and tape recording; protection of confidentiality was fully assured.

Results An agenda on total ban of chrysotile asbestos was proposed to the National Health Assembly, where a resolution was adopted in 2010. The resolution was endorsed by the Cabinet in 2011, which mandated the Ministry of Industry to implement the ban immediately. There was uneven interest and ownership by stakeholders in the policy formulation process. Long delays in implementation have been observed. Furthermore, while the policy is likely to affect relatively few industries there has been misinformation on the safe use of chrysotile, and delaying tactics and pressure from major chrysotileexporting countries.

Conclusion The National Health Assembly is a useful platform for policy formulation on complex policy issues requiring multisectoral action. However, policy implementation is challenging due to lack of clear policy across sectors. Success in protecting people's health requires participatory policy-making and effective governance of multisectoral action throughout implementation. The Assembly is not designed to enforce implementation, especially when power and authority lie with state actors, but monitoring and public reporting would be powerful tools to drive this agenda.

\section{INTRODUCTION: MULTISECTORAL GOVERNANCE FOR HEALTH}

Public participation in the policy-making process has been a contentious issue in Thailand in recent years. This is in response to the conventional policy-making dominated by state actors, with little room for direct citizen participation or deliberation in the public

\section{Key questions}

What is already known?

- Strong scientific evidence that all forms of asbestos are carcinogenic to humans.

- Some industries in Thailand had voluntarily replaced chrysotile asbestos by alternative materials while two others still use them for local consumption and export to ASEAN countries having no ban.

\section{What are the new findings?}

- Despite a National Health Assembly resolution on total ban of chrysotile asbestos which was endorsed by a Cabinet resolution, delays in implementation by a government agency are noted in tandem with fight back by two industries.

- Tactics used by an asbestos-exporting country include threatening the Thai government with trade sanctions; while local industries misinform the public through their media and academic proxies and do not accept international evidence on health hazards.

What do the new findings imply?

- Successful multisectoral action for health depends on good governance of government agencies, strong civil society and political leadership in safeguarding health of people.

- Consistent follow-up and public reporting of progress in implementing the total ban of chrysotile asbestos are recommended as effective tools in holding government accountable.

policy process. ${ }^{1}$ Increasingly, the government sector alone has limited capacities in addressing complex challenges effectively. ${ }^{2}$ Poor governance, weak bureaucratic systems and the competency of government staff hinder the performance of the government sector in dealing with emerging issues. Some people may view that the government, particularly politicians, have their own vested interests in the decision-making. Hence, public participation and increased policy spaces for non-state actors in the decision-making is seen as a counterbalancing mechanism for public policies. $^{3}$ 
In the last decade, there is a growing literature highlighting the importance of multisectoral governance for health. Multisectoral governance for health is defined as the governance mechanisms where several government agencies and non-government actors (including civil society and the private sector) are involved in solving multisectoral, multidimensional health challenges. This mechanism does not lie in a command-and-control type of governance within a single government sector. ${ }^{4}$ Instead, it is regarded as an essential mechanism in addressing complex health challenges created by various determinants outside the health domain. ${ }^{56}$ Multisectoral governance for health is applicable to a wide range of public health policies.

Three types of health policies are relevant to multisectoral governance, with different levels of their complexity.

First, 'win-win' policy: in confronting zoonotic diseases which threaten human security such as the H5N1 outbreaks in 2004; it is compelling that wildlife, animal, agriculture and public health agencies perceive that their institutional mandates could only be achieved by 'working together' to gain mutual benefits. ${ }^{7}$ In this case, multisectoral governance is an enabling tool which facilitates their 'mutual gain'. ${ }^{8}$ Although multisectoral action is feasible in this win-win situation, such as the disease effort, its effective implementation is still a challenge.

Second, 'neutral' or no clear conflict policy: in achieving the reproductive, maternal, newborn, child and adolescent health goals in the sustainable development goals (SDGs), there are many state actors outside the health sector involved, such as agencies responsible for gender equity, food and nutrition security, rural development, economic development and health. ${ }^{9}$ Other stakeholders include intergovernmental organisations as well as civil society organisations. In this case, building a common vision shared by all stakeholders is essential to facilitate multisectoral action in both policy formulation and implementation. Although there are no clear institutional conflicts across government agencies, challenges remain on effective implementation of multisectoral action.

Third, conflicting policy: multisectoral action may face particular challenges, such as when sectoral values and objectives contradict each other or are incompatible with health goals. For example, certain public sector agencies are responsible for trade and economic growth (eg, food, beverage and alcohol) and are, at times, in conflict with health goals to combat NCD and obesity epidemics. ${ }^{10}$ Political trade-offs between public health and economic prosperity could be influenced by societal preferences and the power relations between citizens and government. In such cases, successful multisectoral action needs negotiation skills where compromises are sought across actors. ${ }^{11}$

The nature of multisectoral governance efforts varies throughout the policy cycle of agenda setting, policy development, implementation and evaluation phases, as referred to by Kingdon. ${ }^{12}$ The roles of actors, their skills and resources required for policy formulation are also different from those required for policy implementation. ${ }^{8}$

For instance, under the National Health Assembly (hereafter called the Assembly), Thailand has established a policy formulation process which enables full participation by all sectors including policy makers, the public sector, the academic and technical sectors, the private sector, civil society and the community. This process is mandated by the National Health Act, promulgated in 2007. The Assembly is a platform for multisectoral action for health. ${ }^{13}$ The multisectoral efforts through this Assembly concentrate on policy formulation, monitoring and evaluation, while policy implementation lies in designated agencies, which include government, non-government and community agencies specified in a given resolution. The 2010 Assembly adopted a resolution on a total ban of chrysotile asbestos. The resolution was then endorsed by the Cabinet, making it a legal mandate for the responsible government agencies. Under the National Health Act 2007, the upstream process is carefully designed to ensure full multisector participation for evidence-based policy development, monitoring and evaluation. However, the downstream process for policy implementation faces challenges since there is no mechanism to drive the implementation of the policies adopted.

This paper will address the challenges of policy implementation related to the conflicting policy-the third type of policy, as stated above, on a total ban of chrysotile asbestos. The challenges are related to multisectoral governance and lack of policy clarity among different sectors. The total ban on chrysotile asbestos involves conflicts among health, environmental and industrial interests. It is used as a case study in this paper to understand and illustrate the complexity of multisectoral governance in real practice at two stages of the policy cycle: the policy formulation and implementation by state agencies. This study examines the policy context associated with the chrysotile resolution and actors involved in the policy process, and assesses the way in which multisectoral governance influences the policy implementation. The study concludes by drawing lessons how multisectoral action operates in the context of conflicting goals between health and industrial interests.

\section{METHODS}

The study applies qualitative methods of data collection including in-depth interviews with key informants (KIs) and review of relevant literature, including interventions made by all delegates on the agenda on the total ban on chrysotile asbestos, and media analysis.

\section{Interview of key informants}

The KIs were the most knowledgeable individuals on the subject with adequate representation from health, industry and environment sectors. At the policy formulation level, KIs represent three sectors: the policy/public, academic/technical and private/civil society/community 
Table 1 List of key informants successfully interviewed

\begin{tabular}{lll} 
Stakeholders & $\begin{array}{l}\text { Policy } \\
\text { formulation } \\
\text { phase }\end{array}$ & $\begin{array}{l}\text { Policy } \\
\text { implementation } \\
\text { phase }\end{array}$ \\
\hline $\begin{array}{l}\text { Policy/public sector } \\
\text { Academic/technical sector }\end{array}$ & 3 & 5 \\
$\begin{array}{l}\text { Private/civil society/ } \\
\text { community sector }\end{array}$ & 3 & \\
\hline Total & 9 & 2 \\
\hline
\end{tabular}

who had been involved in the preparation of technical content and manuscripts of the draft resolution. At the policy implementation level, once the resolution was adopted, KI were selected from the Thai Industrial Standards Institute, the Department of Disease Control of the Ministry of Public Health, the Consumer Protection Committee, relevant international organisations and the private sector.

A total of 16 KIs were identified and successfully interviewed without refusals: 9 for the policy formulation phase and 7 for the policy implementation phase. The interviews were conducted between September and November 2013 (table 1).

A semi-structured telephone interview was conducted with all KIs where verbal consent was obtained before the interview. The interview was recorded with permission of the interviewee. Confidentiality was strictly observed, and no KIs' identities are referred to in the study.

Four interview questions for the policy formulation phase include: a) how the agenda was proposed, b) who was involved, c) what was the process of drafting the resolution and d) how was the agreement reached? For the policy implementation phase, four interview questions covered a) the role and responsibility of organisations, b) their positions on total ban on asbestos, c) their plan and strategy for the policy implementation and d) problems and challenges encountered in the policy implementation stage.

Once the interview records had been transcribed, deductive content analysis technique ${ }^{14}$ was used to identify themes and subthemes which emerged from the interviews. All transcripts were read in detail and reread to identify themes, subthemes and patterns from the data. All transcripts were read by CK and TP. After all subthemes and themes were identified, the findings were discussed with VT and WP to synthesise conclusions. Factual content was triangulated across KIs and different documents.

\section{Review of literature and media analysis}

Key literature was reviewed and analysed. This included minutes of the National Health Assembly and its basic documents, the verbatim notes of deliberation during the Health Assembly, minutes of the National Health Commission Committee chaired by the Prime Minister and the Cabinet resolution. Media analysis covered topics

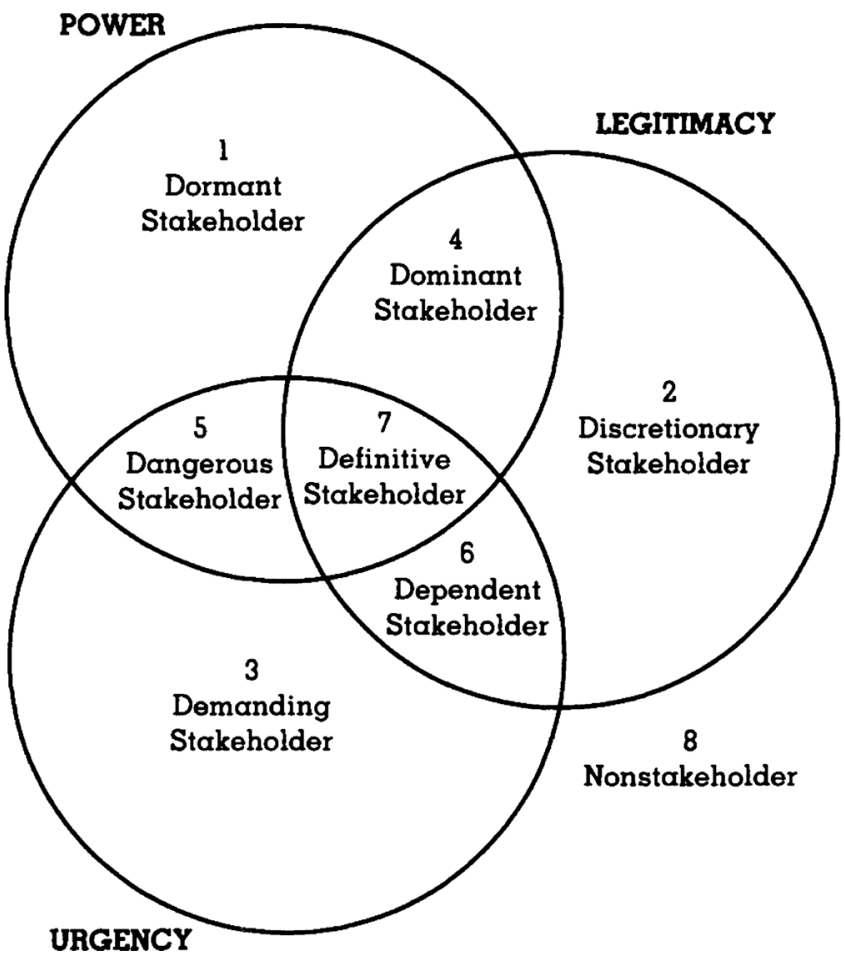

Figure 1 Stakeholder typology: one, two or three attributes present. Source: Mitchell, et al. ${ }^{15}$

on asbestos in three most-read Thai newspapers and relevant websites between 2010 and 2015. They were scanned and analysed on the power and position by different stakeholders, either in favour of, indifferent to or opposed to chrysotile asbestos.

\section{Stakeholder analysis}

The stakeholder analysis ${ }^{15}$ was applied to the analysis of content from the interviews of KIs and the media analysis (figure 1). Seven types of stakeholders were classified by the three attributes, namely legitimacy, power and urgency. Legitimacy is defined as a perception that the actions taken by a stakeholder are desirable, proper or socially appropriate. Power is defined as the extent to which the stakeholder has or can gain access to physical, material, prestige, esteem and social means to impose their positions. Urgency is defined as the degree to which stakeholder's claims call for immediate attention. Definitive stakeholders possess all three attributes (legitimacy, power and urgency), while the intersection of two attributes form three other types of stakeholders: dominant, dependent or dangerous. Stakeholders who possess only one attribute are dormant, discretionary or demanding.

\section{FINDINGS}

\section{Problem steams: strong scientific foundation}

Chrysotile is classified as a hazardous substance type 3, for which production, import, export or possession shall have prior approval by the authority, in this case the Ministry of Industry. The remaining five types of asbestos 
Box 1 Control of hazardous substances by Ministry of Industry

Article 18 of the 1992 Hazardous Substance Act classifies four types of hazardous substance, by level of regulatory intensity. The Ministry of Industry is responsible to announce the types of hazardous substances.

Type 1 is hazardous substances for which production, import, export or possession shall follow the prescribed rule and regulation.

Type 2 is hazardous substances for which production, import, export or possession shall have prior notification to the authority and follow the prescribed rules and regulations.

Type 3 is hazardous substances for which production, import, export or possession shall have prior approval by the authority.

Type 4 is hazardous substances for which production, import, export or possession is forbidden.

According the most update notification, chrysotile is type 3 hazardous substance.

\begin{tabular}{lll}
\hline $\begin{array}{l}\text { Six groups of } \\
\text { asbestos }\end{array}$ & $\begin{array}{l}\text { Registered CAS } \\
\text { number }\end{array}$ & $\begin{array}{l}\text { Type of } \\
\text { regulatory } \\
\text { control }\end{array}$ \\
\hline Crocidolite & $12001-28-4$ & 4 \\
Chrysotile & $12001-29-5$ & 3 \\
Tremolite & $77536-68-6$ & 4 \\
Amosite & $12172-73-5$ & 4 \\
Actinolite & $77536-66-4$ & 4 \\
Anthophylite & $77536-67-5$ & 4 \\
\hline
\end{tabular}

Source: Ministry of Industry: notification of Ministry of Industry, list of hazardous substances 2013. Government Gazette, Volume 130, special part 125d, 27 September 2013. Available at: (https://www.env.go.jp/en/recycle/ asian_net/Country_Information/Law_N_Regulation/Thailand/HW List 5.2 (2013) hazardlist13_eng.pdf accessed 10 November 2016).

(crocidolite, tremolite, amosite, actinolite and anthophylite) were totally banned (box 1 ).

The total value of chrysotile imports into Thailand between 1997 and 2010 was 19.89 billion baht (approximately US $\$ 0.7$ billion), resulting in large economic benefits to various Thai industries that use this substance in a range of products (figure 2 ).

Prior to 2007, the total annual chrysotile import was 142000 tonnes, or 1.8 billion baht (US $\$ 60$ million). After 2007 , when two major manufacturers had voluntarily withdrawn the use of chrysotile, the total import dropped down to 90600 tonnes, or 1.1 billion baht (US $\$ 38$ million) per year. The Russian Federation, China, Brazil and Kazakhstan were the major exporting countries.

Asbestos, a group of natural fibrous minerals, has been used to insulate buildings. It is also used in products such as roofing shingles, water pipes, fire blankets, clutches and brake linings, gaskets and pads for automobiles. The principal forms of asbestos are chrysotile (white asbestos) and crocidolite (blue asbestos); other forms are amosite, anthophylite, tremolite and actinolite. ${ }^{16}$

All forms of asbestos are carcinogenic to humans and can cause mesothelioma and cancers of the lung, larynx and ovary ${ }^{17-24}$ as well as pleural plaques, thickening and effusions. ${ }^{25}{ }^{26}$ WHO estimates that 107000 global annual deaths are caused by mesothelioma, asbestos-related lung cancer and asbestosis. ${ }^{27}$

No threshold has been identified for the carcinogenic risk of chrysotile. Given this epidemiological evidence, WHO recommends stopping the use of all types of asbestos as the most efficient way to eliminate asbestos-related diseases. ${ }^{28}$ This is consistent with the recent International Labour Organisation (ILO) Resolution of $2006^{29}$ promoting the elimination of future use of all forms of asbestos. It should be noted that Thailand has not yet ratified the ILO Convention 162 on Asbestos, which came into force in 1986.

In view of ample evidence of harmful effects of exposure to asbestos, and the WHO and ILO recommendation to prohibit future use of all types of asbestos, the consumer protection group and other stakeholders in Thailand proposed a total ban on chrysotile asbestos to the National Health Assembly in 2010.

\section{Agenda-setting and policy formulation: context and actors}

The international conference on asbestos, convened in Thailand in 2006, adopted the Bangkok Declaration on Elimination of Asbestos and Asbestos-related diseases. ${ }^{30}$ Thailand took this global context to launch a campaign for an asbestos-free Thailand.

The Consumer Protection Committee and the National Economic and Social Advisory Council Consultative Group organised a public hearing on 14 October 2009, which recommended the withdrawal of all asbestos products from the market, they also demanded the dissemination of information to the public, use of fiscal policies to support introduction of substitutes and proper management of asbestos-contaminated waste. In December 2009, the Asian Asbestos Initiative organised a second international seminar in Thailand to share information and research related to the elimination of asbestos-related diseases. $^{31}$

The asbestos agenda was proposed to the Assembly by nine organisations from the three constituencies: academia, civil society and government. Reviews of documents, triangulated by KIs, indicated that the main actors were consumer protection groups, led by the Office of the Consumer Protection Board (a Government body established by the 1979 Consumer Protection $\mathrm{Act}^{32}$ ), the Foundation for Consumers and the Health Consumer Protection programme at Chulalongkorn University.

The content of the Assembly resolution was based on a thorough analysis of evidence by a Technical Working Group (TWG) comprising 17 members (3 experts on asbestos, 1 representative of the private sector, 11 government officers responsible for the issue and 2 from civil society. $^{33}$ Consistently, several KIs confirmed that members of the TWG were knowledgeable about the subject (KI 01 and 05 public sector, KI 02 civil society, KI 03 and 06 academic), and that content of the resolution 


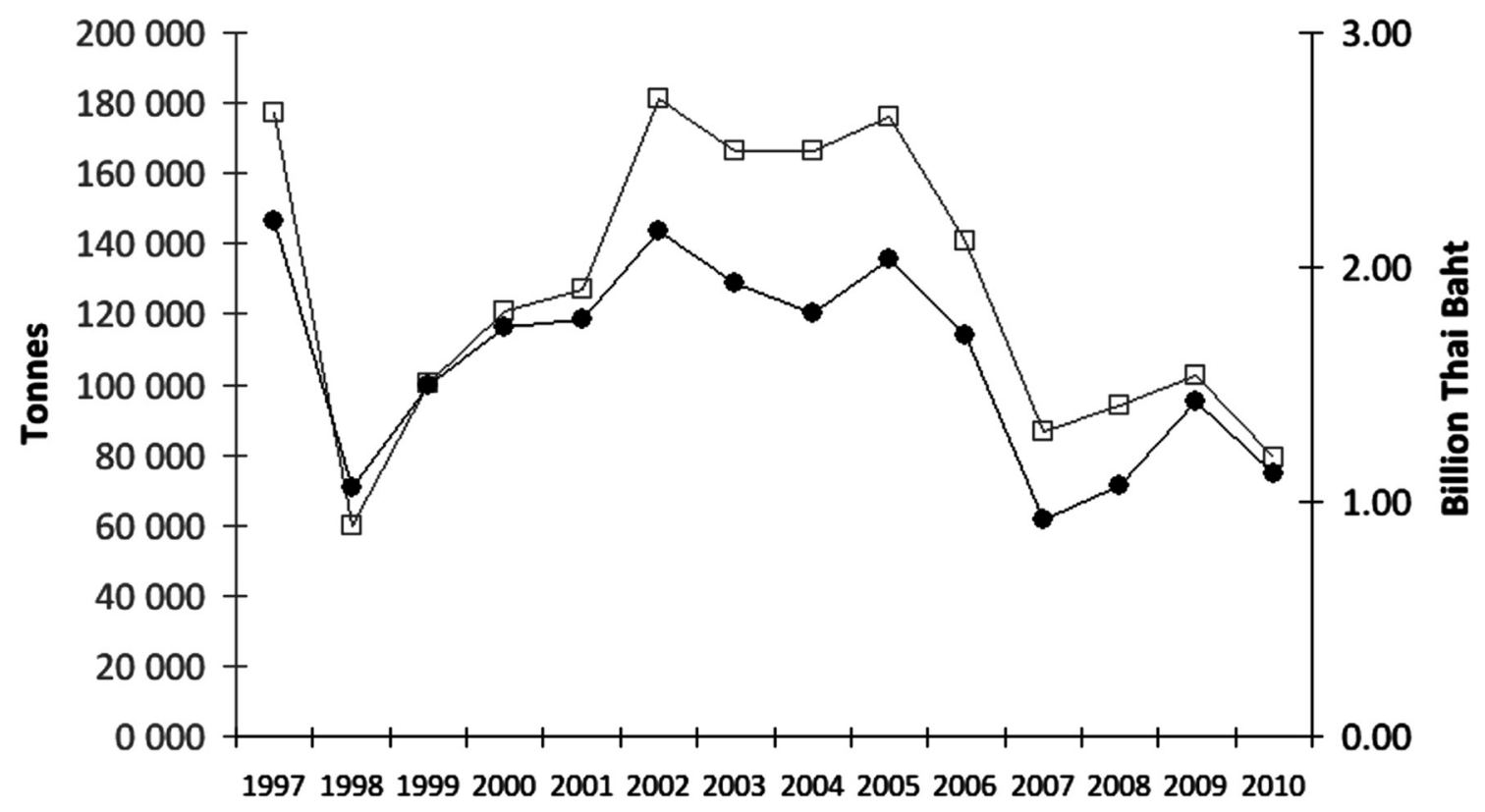

$\longrightarrow$ Imported tonnes $\longrightarrow$-Value of import Billion Thai Baht

Figure 2 Volume and value of asbestos imports, Thailand 1997-2010. Source: Ministry of Finance, Department of Customs 2010.

was based on objective evidence and relevant national and international literature.

In-depth interviews with KIs revealed an uneven level of participation among TWG members. The active TWG members were those who had been involved in the 'asbestos-free' movement since 2006 (KI 01 public sector). The private sector, including a representative from a chrysotile manufacturer, did not participate in drafting the content. The TWG did not reach a consensus on a total ban on chrysotile asbestos, as the member from the industry argued that there was no evidence of health impacts on the Thai population. They argued that international evidence may not be relevant to the Thai population (KI 04 private sector). The draft resolution was nevertheless approved by the TWG and was circulated to other constituencies for comment and feedback, and finally adopted.

At the Assembly deliberations, 20 participants made interventions on this agenda, 6 requested minor amendments on the text, 12 modified wordings and 2 delegates made general comments without proposing amendments. Interestingly, the best-prepared interventions were those from provincial constituencies (table 2). The private sector, represented by the Thai Chamber of Commerce and the Federation of Thai Industries, made no intervention during the deliberation, even though the industry is one of the key actors in the asbestos agenda.

The resolution and the annexed strategy were unanimously adopted by the Assembly on 17 December $2010 .^{34}$ The National Health Commission Office submitted the Resolution for Cabinet endorsement with legal binding for all government agencies for active implementation.

\section{Policy implementation: the power of state actors}

On 12 April 2011, the Cabinet endorsed the Assembly resolution banning chrysotile asbestos, and the Cabinet assigned line ministries to implement the ban. The Ministry of Industry was mandated to prepare a timebound plan for banning production, import, export and distribution of chrysotile asbestos products by listing chrysotile asbestos as a type 4 hazardous substance by 2011, and preparing industrial standards for products containing alternative materials. The Ministry of Finance was mandated to review taxes on substitute products. The Ministry of Public Health, having a keen interest in the health impact from chrysotile, was mandated by the Cabinet as the lead coordinating agency across ministries to implement this resolution. Figure 3 describes key actors with different institutional mandates. Despite the

Table 2 Number of participants making interventions on asbestos agenda, third National Health Assembly in 2010

\begin{tabular}{|c|c|c|c|c|}
\hline Constituency & $\begin{array}{l}\text { Technical } \\
\text { content }\end{array}$ & Wording & $\begin{array}{l}\text { No } \\
\text { amendment } \\
\text { or question }\end{array}$ & Total \\
\hline Provinces & 5 & 10 & & 15 \\
\hline Academia & & & 2 & 2 \\
\hline Private sector & & & & 0 \\
\hline Civil society & & 1 & & 1 \\
\hline Government & 1 & 1 & & 2 \\
\hline Total & 6 & 12 & 2 & 20 \\
\hline
\end{tabular}




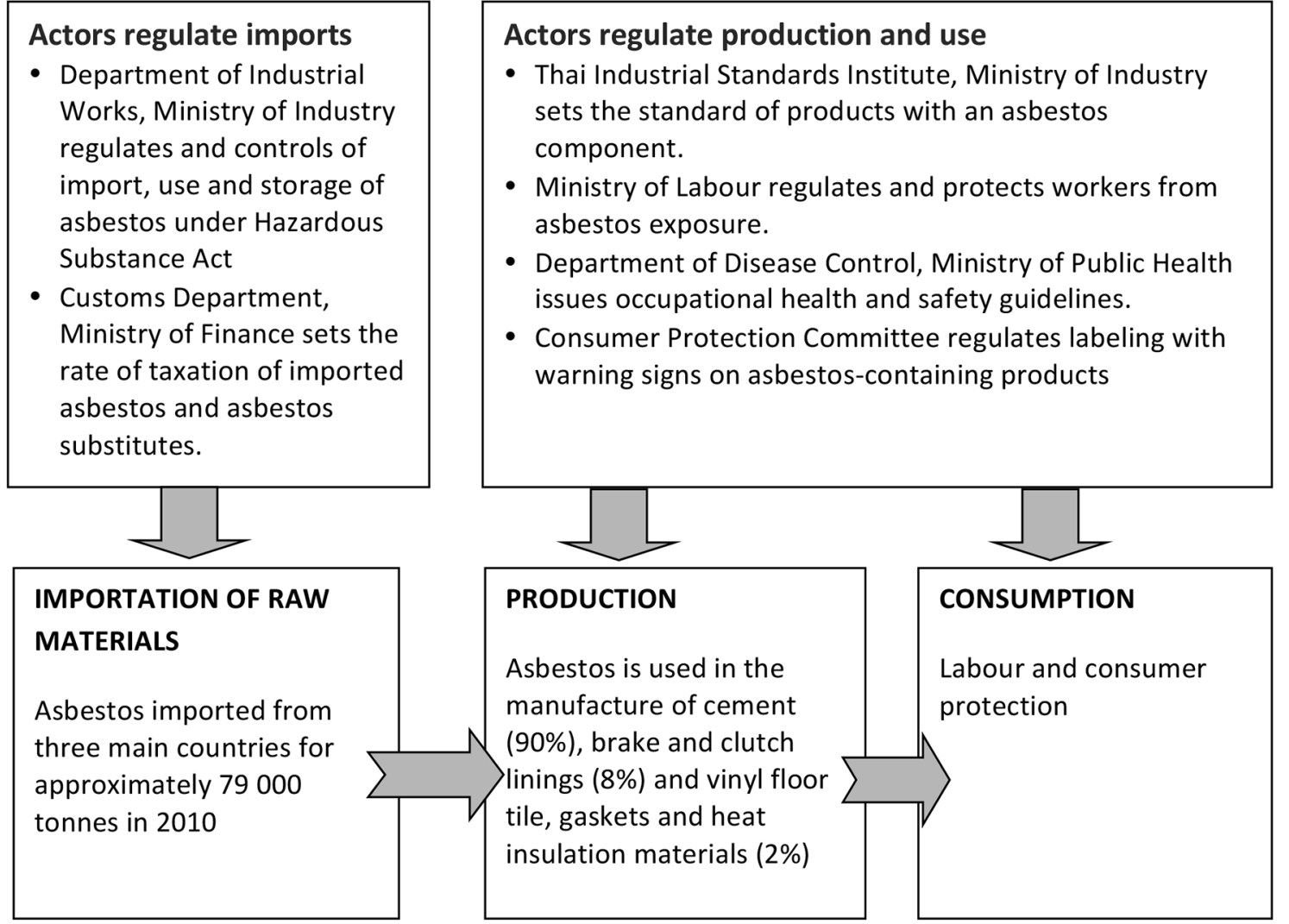

Figure 3 Actors involved in implementation of asbestos control.

Cabinet mandates, however, the implementation of the resolution faced several challenges.

First, the Ministry of Industry convened a stakeholders' forum, reviewed lessons from other countries and selected five priority products containing chrysotile to be banned within 1.5 years. Concern was raised at the time by the KIs on the selection bias that led to the appointment of an academic institute for an advisory role. ${ }^{35}$ The report by the academic institute recommended further study on the health implications of chrysotile, and supported the strengthening of safe use of chrysotile and increased public awareness on safe use. It also raised concerns on the economic impact of export ban on materials containing chrysotile to other ASEAN countries, and the social cost of replacement by alternative materials. The report also confirmed that the current regulations were adequate and it met international standards in terms of safety precautions for chrysotile.

The commissioned report, ${ }^{35}$ therefore proposed a total ban on five out of all products containing chrysotile in 2015, or 5 years after the adoption of the National Health Assembly Resolution in 2010, challenging the Cabinet endorsement of an immediate ban. The commissioned report created two public concerns. First, there was a question of the scientific integrity of the academic institute with regard to the health impact of chrysotile based on the current standard of safe use and recommendation of safe use. Second, regarding the potential 'regulatory capture' of the implementing agency, the industry was seen to have interfered with and influenced the Ministry of Industry to apply delaying tactics. Media sources indicated that the chrysotile industry had mobilised pig farmers to call for the continued use of cheap chrysotile roofing in the pigpens. A media coverage claimed that 'all the roofs of Muslim mosques will be dismantled' in an attempt to stimulate resistance to the ban. These concerns on false information were raised by consumer protection groups at the time (KI 02 Civil society).

Content analysis in newspapers confirmed that a few affected industries, backed by a pulmonary clinician, misinformed the public by stating that no Thai patients are reported to have mesothelioma; and that prospective surveillance is needed. Also the media reported that roof tiles containing chrysotile were sturdier and cheaper than alternative materials, and that replacement of products containing chrysotile with new alternatives would negatively affect agriculture workers, such as the pig farmers. In contrast, the Thai media had not reported counter evidence from industries, which had voluntarily withdrawn chrysotile concerning the endurance and cost of new products. ${ }^{36}$

Second, the Ministry of Commerce had to wait until the Ministry of Industry announced the type 4 hazardous substance ban, before it could fulfil its mandate to ban imports and exports. The Ministry of Commerce was also reluctant to take action as some of the top five asbestos-exporting countries voiced concerns over the ban and exerted political pressure by threatening trade sanctions. 
The Russian Federation trade representative, the International Chrysotile Association and the Chrysotile Information Centre Thailand convened an international conference on 'safe use of chrysotile asbestos: national condition and scientific approach' on 20 November 2014 in Bangkok. Presentations by speakers from Brazil, Canada, India, Thailand (represented by the same academic institute commissioned by the Ministry of Industry and a chest clinician) and Vietnam, highlighted the safe use of chrysotile. This assertion of safe use contradicted the WHO statement by saying that

....there is no evidence for a threshold for the carcinogenic effect of asbestos, including chrysotile, and that increased cancer risks have been observed in populations exposed to very low levels ${ }^{17} 19$

The presentations also highlighted the lack of reports of mesothelioma in Thai patients, and negative economic impact of the ban, such as an estimated cost of 500 billion baht (US\$14 billion) for total replacement, and projections that 4000-5000 workers would be unemployed if the production factory was to close down.

Third, the Office of Consumer Protection under the Office of the Prime Minister is responsible for producing warning labels on asbestos-containing products to create consumer awareness. However, the ban on sales cannot be implemented until the Ministry of Industry has announced that asbestos is a type 4 hazardous substance.

Consumer protection groups in favour of the ban pointed out the conflicting policies in a few key asbestos-exporting countries: while introducing bans to protect their own citizens' health, some countries continued to export these products to other countries (table 3 ).

Finally, the Ministry of Industry is the definitive stakeholder with the critical power either to block or support the implementation of the resolution (KI 01 public sector, KI 02 civil society). Due to conflicting views at the definitive stakeholder level, a total ban has unfortunately been delayed. Understanding the hazards associated with asbestos is complex and, in this case, was manipulated by affected industries and their proxies, through false information, advocating the safe use of chrysotile, and arguing that current practice in Thailand was safe and up to international standards. Industry also stressed the low cost and durability of asbestos-containing products, and the higher cost of alternative materials for farmers and the poor.

\section{DISCUSSION}

This study focused on multisectoral governance in two stages of the policy cycle: policy formulation and implementation. The strengths and limitations of multisectoral governance in the case of chrysotile in Thailand are discussed and policy lessons have been drawn.

\section{Multisectoral governance for health in policy formulation}

The highly democratic and participatory processes of the Assembly was successful, leading to a consensus in the adoption of the Resolution. The endorsement of the Resolution by the Cabinet further strengthened the legal status. Although the multisectoral action process of the Assembly was successful in adopting a resolution and receiving endorsement by the Cabinet, there were a few limitations.

First, the industry representatives kept silent in the Assembly process by not voicing their concerns 'on the negotiation table'. A few KIs reflected that, probably they (the industry representatives) felt it unwise to confront the majority of the constituencies who were in favour of a chrysotile ban. Also, they may not be familiar with or convinced by the multisectoral action procedures. Hence, manipulation outside the Assembly process was a preferred approach to influence policy implementation. In view of their economic interests, the relevant industries are not yet ready to comply with the ban.

Second, the consumer protection organisations were not so successful in mobilising a strategic alliance with two major manufacturers, which had voluntarily stopped using Chrysotile in 2007. Consumer protection organisations reflected in the media that they (the two major manufacturers) should have provided public information on the cost and durability of alternative materials.

Third, the Ministry of Public Health (MOPH), as the national health authority has a sense of urgency and a legitimate role to play in protecting the public from exposure to carcinogenic substances, but lacks power in policy implementation. The MOPH has two (legitimacy and urgency) out of the three attributes (legitimacy, urgency and power) to be a 'definitive stakeholder' (figure 1).

Table 3 Top world producers of asbestos, tonnage and status of in-country ban, estimates for 2015

\begin{tabular}{|c|c|c|}
\hline Country & Production (tonnes) & Status of asbestos ban in country \\
\hline China & 400000 & $\begin{array}{l}\text { Bans asbestos for friction materials in the automobile industry: GB 12876-1999: } \\
\text { Road Vehicle Braking Systems - Structure, Performance and Test Methods }\end{array}$ \\
\hline Brazil & 311000 & $\begin{array}{l}\text { Bans asbestos, as do many towns and cities. São Paulo State law } 12.684 / 07 \\
\text { prohibits the use of any product containing asbestos, formally upheld by the } \\
\text { Brazilian Supremo Tribunal Federal }\end{array}$ \\
\hline
\end{tabular}

Source: The United States Geological Survey Minerals Resources Program, 2015 and various other sources compiled by the authors. 
Hence, the MOPH is classified as a dependent stakeholder as defined by Mitchell et al. The cabinet resolution may have wrongly entrusted the MOPH, the non-definitive stakeholder, as lead agency, as it lacks power to list chrysotile asbestos as a type 4 hazardous substance. But KIs explained that the MOPH should be the lead agency responsible for convening meetings, following up on progress with multiple ministries and coordinating the implementation of integrated strategies on chrysotile.

Similar to the MOPH, the Ministry of Commerce and the consumer protection groups were the dependent stakeholders that had legitimacy in terms of consumers' health protection, and a real sense of urgency. The Ministry of Commerce could become a definitive stakeholder (possessing all three attributes) only when the Ministry of Industry announces chrysotile as a type 4 hazardous substance, and bans import, export and the possession of chrysotile.

From the document analysis and interviews with KIs, the Ministry of Industry should have been the definitive stakeholder, but it failed to handle the issue as a matter of public health urgency. As the custodian of the Hazardous Substance (Control) Act it has the power and legal authority to a total ban of chrysotile by listing it as a level 4 hazardous substance. It has also legitimacy-the right and acceptance of an authority, governed by the law. The Ministry of Industry has two out of three attributes to be a definitive stakeholder and, hence, is classified as the dominant stakeholder. This case reflects an imbalance of power and interests across the involved ministries. Political instability in Thailand during 2011-2014 further impeded radical reform.

\section{Multisectoral governance for health in policy implementation}

Efforts to drive multisectoral action on determinants of health have often stalled at the implementation phase. Even when policy makers agree with the rationale and approach $^{11}$ on health policy issues, there are deficiencies in the governance, financing and joint monitoring of multisectoral action to achieve targets. ${ }^{11}$ The National Health Commission thus appointed a committee in 2015, chaired by the Public Health Minister, to follow-up on the progress of policy implementation on all health resolutions. This mechanism is expected to fill the implementation gap and support coordination work among different actors.

Despite the Cabinet's endorsement, implementation became entangled in 'regulatory capture' of the Department of Industrial Works, Ministry of Industry, as observed by one of the KIs from civil society.

If government actors were fully convinced by National Health Assembly resolutions, implementation would be smooth and successful, especially in win-win scenarios. In the win-lose case of chrysotile, however, a few industries have fought hard to protect their interests, and effective implementation has been difficult as highlighted above. Also, the weak and fragmented coalition among consumer protection groups and lack of public interest cannot match the industrial interest, and its financial power to influence media coverage on the issue, leading to the suspension of policy implementation.

\section{Misinformation and external pressure}

An aggressive misinformation campaign was also carried out to promote the safe use of chrysotile. Furthermore, arguments by a chest clinician that there were reports of Thai patients with mesothelioma, probably reflects the fact that such patients were undiagnosed. The development of mesothelioma takes more than two decades of continuous exposure. It requires expensive CT and investigations for diagnosis, which are out of reach of most low-income blue-collar workers (if the medical bills are to be paid from their own pocket ${ }^{37}$ ). It should be noted that, if a series of tests such as imaging scans and blood tests indicate a potential for mesothelioma, a tissue biopsy is required for a histological diagnosis of mesothelioma. Therefore, chest film alone cannot be used to diagnose mesothelioma, as wrongly argued by the chest clinician.

Typically in Thailand, chest screening for occupational diseases is done only by normal chest X-ray, which cannot detect mesothelioma. Therefore, this condition remains poorly documented. In Europe, with better clinical records, between 1994 and 2010 there were 106180 registered deaths from mesothelioma and asbestosis. That number accounted for $60 \%$ of worldwide deaths from asbestos-related illnesses in that time period. ${ }^{27}$ Nonetheless,industry-supported dissemination of misinformation continues despite the MOPH and academia revealing hard international evidence. Stakeholders opposing to the ban have demanded local evidence on the health impact of asbestos exposure, thereby ignoring the substantial body of international evidence, such as reports by WHO, the International Agency for Research on Cancer and the ILO. ${ }^{1624} 29$

A total ban on chrysotile affects countries exporting asbestos to Thailand, in particular, the top three countries of the Russian Federation, China and Brazil. From a media analysis, there were organised and systematic counteractions by the industry, trade representatives and their proxies such as convening an international conference in Bangkok on safe use of chrysotile and propagating misinformation to the public. The conference was led by the International Chrysotile Association and the Chrysotile Information Centre Thailand. The total ban would affect Thai industries' ability to export chrysotile-containing materials to ASEAN countries where chrysotile is not banned (this includes all countries except Singapore and Brunei Darussalam). Without very strong political leadership protecting the health of the people, industrial interests prevail.

This study discussed the contentious issue of multisectoral governance for health, in particular a resolution on banning chrysotile asbestos. The policy implementation was delayed because of the bureaucracy involving a government agency and two industries. A tactic was used by an asbestos-exporting country to threaten Thailand 
with trade sanctions, while the local industry misinformed the public through media and academic proxies. They did not accept international evidence on potential health hazards of chrysotile asbestos in any amount.

Policy interference by the asbestos industry shares similar tactics applied by the tobacco and alcohol industries. Their tactics include public relations campaigns, using alternative scientific and other findings to create controversy about established facts, funding political parties and hiring lobbyists to influence policy, using front groups to oppose regulatory and control measures, pre-empting strong legislation by pressing for the adoption of voluntary codes or weaker laws, and corrupting public officials. ${ }^{38}$ Legal threats and filing law suits against governments are common practices by the tobacco industry. ${ }^{39}$

\section{CONCLUSION}

The case of banning chrysotile asbestos is a good lesson on the challenge of health policy governance in Thailand. To a large extent, the Assembly contributes significantly to citizen participation and deliberations in agenda-setting, policy formulation, the adoption of a resolution and the Cabinet's endorsement of the health policy. The role of consumer protection groups is critical; they synthesise evidence and heighten attention to the problem, lead agenda setting and the adoption of the resolution of the National Health Assembly.

For this case however, progress in implementation was slow because power remained with the Ministry of Industry, which failed to act due to its lack of ownership of the agenda and the fact that it did not share a common concern about the health of workers and the community. In this case, there is no definitive stakeholder, hence, there was limited success in implementation.

Success in safeguarding public health is often determined by the degree of good governance among government implementing agencies. In a win-lose scenario, possible 'policy capture' may derail or delay the policy implementation. This case was further complicated by resistance from a few affected domestic industries and pressure from chrysotile-exporting countries.

Effective multisectoral actions for health at the implementation level require good governance in implementing agencies, stronger civil society and political leadership in safeguarding the health of the people, sharing a common goal of protecting the health of people and common solutions regarding affordable alternative replacements. Above all, the policy implementation should be governed by appropriate accountability and effective state agencies. ${ }^{8}$ We recommend parallel mechanisms to monitor the progress of the implementation of Cabinet resolutions, and regular public report on the issue. Parallel mechanisms can be effective tools to improve the accountability of government agencies.

Acknowledgements The authors acknowledge the contributions by all key informants to this study and for their frank input and discussion as well as staff at the National Health Commission Office in enabling access to documents. This study is part of the BMJ Global Health supplement on 'Governing Multisectoral Collaborations for Health' edited by Bennett S, Rasanathan $\mathrm{K}$ and Abimbola S.

Contributors CK designed the research, conducted the interviews, searched literature, data analysis and drafted the manuscript and circulate to coauthors for comments and feedback. VT contributed in designing the research, conducted the interviews, searched literature, data analysis and provided comments, revised the drafted manuscript. WP contributed in designing the research, conducted the interviews, provided comments, revised the drafted manuscript. TP contributed in designing the research, conducted the interviews, searched literature, data analysis and provided comments, revised the drafted manuscript.

Funding This work was funded by the National Health Commission Office.

Disclaimer The National Health Commission Office does not have any influence on the design and findings of this study.

Competing interests None declared.

Patient consent Not required.

Ethics approval The study was approved by the Mahidol University Human Research Ethics Committee.

Provenance and peer review Not commissioned; externally peer reviewed.

Open access This is an open access article distributed in accordance with the Creative Commons Attribution Non Commercial (CC BY-NC 4.0) license, which permits others to distribute, remix, adapt, build upon this work non-commercially, and license their derivative works on different terms, provided the original work is properly cited and the use is non-commercial. See: http://creativecommons.org/ licenses/by-nc/4.0/

(C) Article author(s) (or their employer(s) unless otherwise stated in the text of the article) 2018. All rights reserved. No commercial use is permitted unless otherwise expressly granted.

\section{REFERENCES}

1. Przeworski A, Stokes SC, Manin B. Democracy, Accountability and Representation. Cambridge: Cambridge University Press, 1999

2. Kickbusch I, Gleicher D. Governance of Health in the 21st Century. Copenhagen: WHO European Regional Office, 2012.

3. Smith J, Buse K, Gordon C. Civil society: the catalyst for ensuring health in the age of sustainable development. Global Health 2016;12:40.

4. Rasanathan K, Bennett S, Atkins V, et al. Governing multisectoral action for health in low- and middle-income countries. PLoS Med 2017;14:e1002285.

5. Fawcett S, Schultz J, Watson-Thompson J, et al. Building multisectoral partnerships for population health and health equity. Prev Chronic Dis 2010;7.

6. Willis CD, Greene JK, Abramowicz A, et al. Strengthening the evidence and action on multi-sectoral partnerships in public health: an action research initiative. Health Promot Chronic Dis Prev Can 2016;36:101-11.

7. Marano N, Arguin P, Pappaioanou M, et al. Role of multisector partnerships in controlling emerging zoonotic diseases. Emerg Infect Dis 2005;11:1813-4.

8. Public Health Agency of Canada. Crossing Sectors - Experiences in Intersectoral Action, Public Policy and Health, 2007.

9. Rasanathan K, Damji N, Atsbeha T, et al. Ensuring multisectoral action on the determinants of reproductive, maternal, newborn, child, and adolescent health in the post-2015 era. BMJ 2015;351:h4213.

10. Ruckert A, Schram A, Labonté R, et al. Policy coherence, health and the sustainable development goals: a health impact assessment of the Trans-Pacific Partnership. Crit Public Health 2017;27:86-96.

11. Ståhl T, Wismar M, Ollila E, et al, eds. Health in All Policies Prospects and potentials. Helsinki: Ministry of Social Affairs and Health, Health Department, Finland \& European Observatory on Health Systems and Policies, 2006.

12. Kingdon JW. Agendas, alternatives and public policies. Boston, MA and Toronto: Little, Brown and Company, 1984.

13. Rasanathan K, Posayanonda T, Birmingham M, et al. Innovation and participation for healthy public policy: the first National Health Assembly in Thailand. Health Expect 2012;15:87-96.

14. Pope C, Ziebland S, Mays N, et al. Analysing qualitative data, in Qualitative research in health care. London: BMJ Group, 2006:63-81. 
15. Mitchell R, Agle B, Wood D. Toward a Theory of Stakeholder Identification and Salience: Defining the Principle of Who and What Really Counts. Academy of Management Review 1997;22:853-86.

16. World Health Organization. Asbestos: elimination of asbestos-related diseases. 2010. Fact sheet $N^{\circ} 343$ July 2010. http://www.who.int/ mediacentre/factsheets/fs343/en/index.html (cited 30 Oct 2013).

17. Pira E, Pelucchi C, Piolatto PG, et al. Mortality from cancer and other causes in the Balangero cohort of chrysotile asbestos miners. Occup Environ Med 2009;66:805-9.

18. Hein MJ, Stayner LT, Lehman E, et al. Follow-up study of chrysotile textile workers: cohort mortality and exposure-response. Occup Environ Med 2007;64:616-25.

19. Loomis D, Dement JM, Wolf SH, et al. Lung cancer mortality and fibre exposures among North Carolina asbestos textile workers. Occup Environ Med 2009;66:535-42.

20. National Cancer Institute at the National Institute of Health. Asbestos exposure and cancer risk. Fact sheet. 2009. cited 14 Nov 2013. http://www.cancer.gov/cancertopics/factsheet/Risk/asbestos

21. Goldberg M, Luce D. The health impact of nonoccupational exposure to asbestos: what do we know? Eur J Cancer Prev 2009;18:489-503.

22. McCormack V, Peto J, Byrnes G, et al. Estimating the asbestosrelated lung cancer burden from mesothelioma mortality. $\mathrm{Br} J$ Cancer 2012;106:575-84

23. LaDou J, Castleman B, Frank A, et al. The case for a global ban on asbestos. Environ Health Perspect 2010;118:897-901.

24. International Agency for Research on Cancer Monograph Working Group,. A review of human carcinogens-Part C: metals, arsenic, dusts, and fibres. Special Report: Policy. Lancet Oncology 2009;10:453-4.

25. World Health Organization,. Environmental Health Criteria 203 Chrysotile Asbestos. Geneva: World Health Organization, 1998.

26. World Health Organization. Environmental Health Criteria 53: Asbestos and Other Natural Mineral Fibres. Geneva: World Health Organization, 1986.

27. Kameda T, Takahashi K, Kim R, et al. Asbestos: use, bans and disease burden in Europe. Bull World Health Organ 2014;92:790-7.

28. World Health Organization. Elimination of asbestos-related diseases. Geneva: World Health Organization, 2006. WHO/SDE/OEH/06.03.
29. International Labour Organization. Resolution concerning asbestos, 2006. The 95th Session of the International Labour Conference, June 2006. $2006 \mathrm{http}: / / \mathrm{www}$.ilo.org/safework/info/standards-andinstruments/WCMS_108556/lang-en/index.htm (cited 8 Sep 2014).

30. The Bangkok Declaration on Elimination of Asbestos and Asbestosrelated Diseases. $2006 \mathrm{http}: / /$ www.dpck5.com/download/boss_ sep49_07.pdf (cited 26 Dec 2013).

31. Kazan-Allen L. 2009 International Ban Asbestos Secretariat Report. Asian Asbestos Conference, Hong Kong;April 26-27;2009.

32. Consumer Protection Act, B.E. 2522. A.D. 1979. http://www. thailawforum.com/database1/ConsumerProtecting-law.html (cited 17 Nov 2013).

33. National Health Commission Office. Order of Technical SubCommittee under National Health Assembly Organizing Committee number 1/2553 appointing technical working group for drafting policy proposals (in Thai). 2010.

34. Third National Health Assembly. Measures to make Thai society free from asbestos. Resolution 5 Agenda Item 2.5, 17 December 2010. 2010. cited 17 Nov 2013. http://en.nationalhealth.or.th/sites/default/ files/Resolution_asbestos.pdf

35. King Mongkut's Institute of Technology Ladkrabang. Analysis, review and recommendation on safe use of Chrysotile 2013 (Thai report). 2013 http://www.amc.kmitl.ac.th/research/faculty/form/income/ project_tirasak.pdf (accessed 6 Nov 2016).

36. Bangkok Post, The battle to ban asbestos: Its health risks are well documented, but some Thai industry leaders insist the material can be used safely and are digging in against a push to outlaw it. 2014. http://www.bangkokpost.com/print/446179/ (accessed 10 Nov 2016).

37. Sooksringam B. Asbestosis: lung cancer from asbestos: Burapa University, 2009. A research report (in Thai).

38. Saloojee Y, Dagli E. Tobacco industry tactics for resisting public policy on health. Bull World Health Organ 2000;78:902-10.

39. Tobacco companies file lawsuits against UK Government over plain packaging laws. http://www.independent.co.uk/life-style/health-andfamilies/health-news/tobacco-companies-file-lawsuits-against-ukgovernment-over-plain-packaging-laws-10270874.html (accessed 10 Mar 2017). 